\section{ABNORMALLY LONG VERMIFORM APPENDIX *}

\section{H. P. COLE, M.D., ANd GILMAN J. WinTHRoP, M.D. MOBILE, ALA.}

The average length of the appendix, as stated by different authors, is from 8 to $11.5 \mathrm{~cm}$ (3 to $4 \frac{1}{2} \mathrm{in.}$ ), with a mean of $9.2 \mathrm{~cm}$. (Kelly, Ribbert and Berry place it at about $8.3 \mathrm{~cm} ., 31 / 4$ in.), or between 3 and $31 / 3$ inches. Abnormally long appendices have been noted by J. D. Blake (24 cm.- $91 / 3$ in.), Lafforge (24 cm.$91 / 3$ in.), Luschka ( $23 \mathrm{~cm} .-9$ in.) and Lenzmann (22 cm. $-8 \%$ in.). Below we report a case in which we removed an appendix $20.9 \mathrm{~cm}$. (81/4 in.) in length, about two and one-half times the normal length.

History.-The patient was a mulatto woman, aged 31 years, having what we diagnosed clinically as a myoma of the uterus and an ovarian cyst (left).

Operation.-On Dec. 3,1908, under ether anesthesia, a pedun culated myoma 13.5 by 13 by $13 \mathrm{~cm}$. ( $51 / 5$ by 5 by 5 in.) was removed by tying and cutting the pedicle. A large ovarian cyst, together with the Fallopian tube, was removed from the left broad ligament. A small cyst was removed from the right ovary. On looking for the appendix almost complete absence of the mesoappendix was noted. The appendix lay in the second most frequent position ascending vertically behind the cecum and first portion of the colon, and partially attached to the dorsal wall of the large intestine. The tip extended to the level of the upper pole of the kidney. Considerable difficulty being experienced in freeing the appendix, its peritoneal coat was incised at the cecal junction and the appendix then stripped and dissected free from this covering. The stump was ligated and inverted into the cecum by the usual purse-string method. The uterus was then suspended and the abdomen closed without drainage. The patient made an uneventful recovery and left the hospital twelve days after the operation.

This appendix had apparently given no symptoms. It was probably drawn into the ascending position by the formation of early adhesions between the appendix and the other organs lying posterior to the cecum at the time of its descent, as suggested by Kelly. Removal was undertaken because of the more frequent occurrence of inflammation in appendices lying in this position. 204 Conti Street.

\section{TECHNIC IN TRANSFUSION}

\section{HERMANN B. GESSNER, M.D.}

Professor in the Miles Laboratory of Operative Surgery, Tulane University of Louisiana NEW ORLEANS

In experimental work in the laboratory, in which I have had the assistance of Dr. W. Lassiter, we hav found the use of the fine tenacula of the Elsberg outfit advantageous in doing transfusion experiments on the lower animals with the Crile tube. 'The tenaculum is thrust through the Crile tube, hooks the artery by the circumference, and draws it through more quickly and with less traumatism than when sutures are used for the purpose or the artery is pushed through. The artery once arawn through, a second tenaculum suffices to cuff the extremity over the Crile tube. Here the cuff may be secured with a ligature over one of the grooves or, if desired, it can be held in place with the two tenacula while with two more the recipient vessel is drawn over the culfed donor vessel and a single ligature used to hold both over the tube.

'The advantages are ease of performance, a minimum of traumatism, and economy of time. 506 Morris Building.

* Read before the Medical Society of Mobile County, Ala., Jan. 29,1909 .
ACUTE MILIARY TUBERCULOSIS FOLLOWING RENAL TUBERCULOSIS, SECONDARY TO OLD HEALED BILATERAL APICAL TUBERCULOSIS

PAUL H. RINGER, A.B., M.D. ASHeVille, N. c.

The following case may be of interest to many as being to a great degree illustrative of the relations of cause and effect in the mobilization of tubercle bacilli after an apparent cure has been effected. In the case reported here no knowledge of the primary disease was obtained until the autopsy, the patient having died from general dissemination. A point of special interest is the intermediate route chosen by the tubercle bacilli, and their temporary halting place in the right kidney before spreading to the body at large.

Patient.- I was called on July 19, 1909, to see Mr. J. C., aged 28, a farmer from Kentucky, who had been in Asheville three weeks. Data were obtained from his wife.

History.-Mother and several brothers died of pulmonary tuberculosis. Patient well as a child; no past illnesses; was an athlete at college. About a year before this illness he had had "attacks" consisting of severe pain in the region of the bladder. These attacks came on after he had worked very hard building a house. The pain caused vomiting. These attacks recurred several times, and finally stopped. About six months before the present illness he had "stomach trouble" (nature very obscure), and his home physiciain said he had too much acid in the gastric juice; this was counteracted by an alkali. Three months before the present illness the patient began to run an irregular temperature and to lose weight and strength. For the past two months the temperature had been constant, ranging from 99 to 102 . At no time had there been actual cough; there had been transient expectoration ascribed to "catarrh.". The patient was examined in April, 1909 , and was told that his lungs were weak but that the physician did not think it was tuberculosis. It was understood from what could be elicited from his wife that a Moro cutaneous tuberculin test was given-result not positive. The patient had been kept in bed for a month at home and then sent to Asheville. While here he was constantly in bed, growing steadily worse. His bowels were somewhat loose; he was said to be voiding a normal amount of urine.

Examination (July 19).-Patient poorly nourished, sallow and pale; dorsal decubitus; expression anxious. Evidently much loss of weight. Pupils equal, reacting both to light and to accommodation, though somewhat sluggishly. Tongue heavily coated. Throat apparently normal.

Chest: Note over all normal save for possible hyperresonance over the upper lobes. Breath-sounds normal over all. A few subcrepitant râles heard on deep breathing and on coughing in first right and left intercostal spaces. Also a few rîles on left side in anterior and mid-axillary lines down to about the eighth rib. No adventitious sounds behind.

Abdomen: Tender over all. Liver, spleen and gall bladder not palpable. Some tympanites; no rose-spots. In hypogastric region there was a large tumor half the size of an adult head, sharply defined, smooth, tense, flat on percussion. It was in the region of the bladder and very tender to pres. sure. Patient voided about 12 ounces of urine on request. This was examined and found to be acid, sp. gr. 1,016, trace of albumin, moderate amount of pus, no other abnormality. Patient semidelirious for past three days-cerebration slow. Tried to get out of bed.

Course of Disease.-Owing to the inaccessibility of the patient's house and to lack of proper facilities for caring for him, he was brought to the Asheville Mission Hospital on the morning of July 20 . During the night of the 19th he was given morphin gr. $1 / 8$, which kept him fairly quiet. The next morning, July 20 , he drove three miles and was admitted to the hospital at 11:45 a. m. suffering from a hard chill. At 1 p. m., the abdominal tumor persisting, and having seemingly increased in size, he was catheterized and 53 ounces of urine 